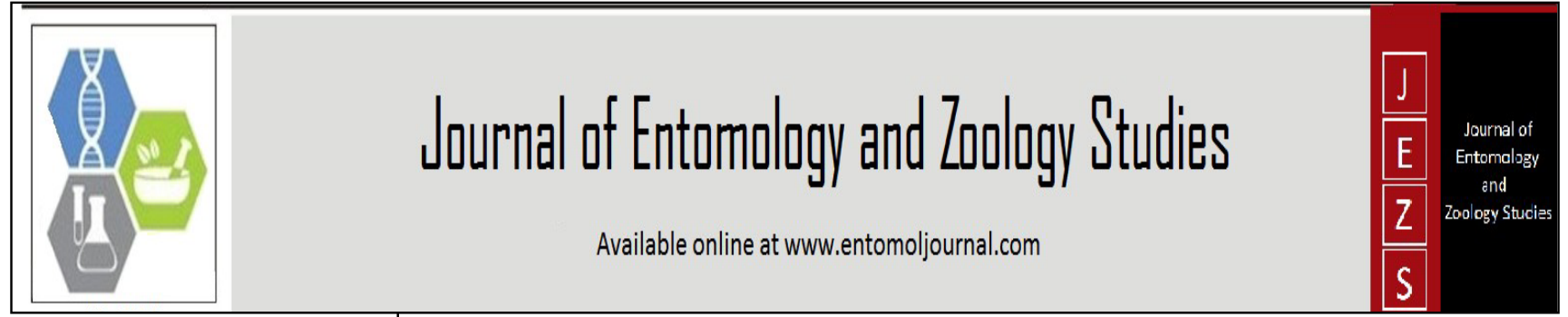

E-ISSN: 2320-7078 P-ISSN: 2349-6800 JEZS 2017; 5(3): 499-506

(C) 2017 JEZS

Received: 11-03-2017 Accepted: 12-04-2017

Amir Sohail Choudhury

Wildlife Conservation

Laboratory, Department of

Ecology and Environmental

Science, Assam University,

Silchar, India

Parthankar Choudhury Wildlife Conservation Laboratory, Department of Ecology and Environmental Science, Assam University, Silchar, India
Correspondence

Parthankar Choudhury Wildlife Conservation Laboratory, Department of Ecology and Environmental Science, Assam University, Silchar, India

\section{Conservation concern to the primates outside protected areas: A study from Hailakandi, Assam, India}

\section{Amir Sohail Choudhury and Parthankar Choudhury}

DOI: http://dx.doi.org/10.22271/i.ento.2017.v5.i3h.01

\section{Abstract}

From December 2015-April 2016 and October-December 2016 we undertook a survey for eight months to document the recent status of occurrence and threats of primates at Hailakandi (Assam). As a result, we found Rhesus macaque were the most common primates species $(90 \%$ occurrence) while threatened species like Capped langur as fairly common (68\% occurrence), Phayre's leaf monkey as uncommon ( $43 \%$ occurrence) and Hoolock gibbon remain to be as rare (37\% occurrence). In priority rating, Hoolock gibbon scores 9 high for any primate species, this is followed by Stump-tailed macaque scores 8 and Assamese macaque scores 7 analogues to Slow loris while Phayre's leaf monkey scores 6 irrespective of its threatened status. Thus, the species score near to or equal to 11 would indicate an urgent attention for conservation. Among conservation issues habitat loss, illegal encroachment and poaching were supposed to be major issues of concern. Besides lack of awareness and scientific study also devoid this area from better conservation practice. At last, it is hope that the present area could make significant contribution to the survival of these globally threatened primate species if right conservation strategies are implement in time.

Keywords: Assam, conservation, Hailakandi, primate, priority rating, threatened

\section{Introduction}

Assam, a northeastern state of India, attracts many naturalists across the globe for the great variety of wildlife it possesses ${ }^{[11,12]}$. High diversity of wildlife signifies enormous diversity of habitats in this region due to which assemblage of threatened to a most common species is not unusual. In Assam, nine species of Primates are found out of 14 in India, which includes five 'Endangered' and four 'Vulnerable' ${ }^{[10-14]}$. This is high for any Indian state. Such richness in wildlife diversity is mainly due to the unique geographic location. The state is located between the transitional zone of Indian sub-region (lies to the north of Brahmaputra River) and IndoChinese sub-region (lies to the south of Brahmaputra River) ${ }^{[10,21,19]}$. Assam also forms a part of two biodiversity hotspots: Indo-Burma and Eastern Himalaya [10, 21, 19]. Physiographically, the state is divided into plains constituted by Brahmaputra valley (north) and the Barak valley (south) and hilly tracts formed by NC Hills, parts of Cachar and Karbi Analong, and Barail range forms the highest hill range $(1950 \mathrm{~m})$ in Assam ${ }^{[10]}$.

The district Hailakandi is located at the southern part of the state covering an area of 1327 $\mathrm{km}^{2}$. Out of total land cover $538.35 \mathrm{~km}^{2}$ is under Inner line Reserve forest and Katakhal Reserve forest while total forest canopy cover is about $786 \mathrm{~km}^{2}{ }^{[16]}$. Major forest type in these reserve forests are Cachar tropical wet evergreen forest with small patch of semi evergreen forests containing some tropical deciduous forest ${ }^{[3,5]}$. While large patches of forest cover is devoid of primary tree covering as in many areas of the reserve forests have fragmented, secondary vegetation have come up interspersed with human settlement. Monoculture orchards and crop fields are some of the common features in such areas ${ }^{[20]}$. Adjacent monoculture areas and tea cultivation merges with fringe forest at places are the causes for such amalgamation. However, these mixed habitat types indeed support high primate diversity.

Currently the forest areas of the district provide shelter to eight non-human primates of which two are 'Endangered' and four are 'Vulnerable'. Bengal Slow Loris Nycticebus bengalensis (Family Lorisidae), Hoolock gibbon Hoolock hoolock (Family Hylobatidae), Capped langur Trachypithecus pileatus, Phayre's langur Trachypithecus phayrei (both under Family Cercopithecidae, Subfamily Colobinae) and Assamese macaque Macaca assamensis, Pigtailed macaque Macaca nemestrina, Stump-tailed macaque Macaca arctoides and Rhesus 
macaque Macaca mulatta (all from Family Cercopithecidae, Subfamily Cercopithecinae) ${ }^{[5,10,12,14,21]}$. While Phayre's Leaf monkey is much noteworthy as it occur in significant proportion in these reserve forests of Assam [1, 6, 9, 11]. The river Barak acts as barrier for this species, therefore it is limited to the south bank of the river ${ }^{[4,6,9,11,13]}$. In addition to these primate species, the occurrence of Silvered leaf monkey Trachypithecus cristatus has been reported which need further

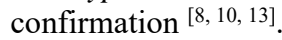

Sharp decline in mammalian population is quite evident in these reserves since the beginning of $20^{\text {th }}$ century. Rapid habitat loss and hunting are supposed to be their prime threats $[4,5,11,12,13,20]$. Ironically, no major conservation measures have been taken up in the area till date; obviously, assessment of primate status and conservation issues has remained hitherto unaddressed. Therefore, the present article is prepared to provide present occurrence status and prevailing conservation issues for the primates of Hailakandi. Additionally, we prioritise each primate species using priority rating in order to identify the species that require an urgent conservation attention by best use of available limited resource for primate conservation. Hence, this work is of immense potential in the field of primate conservation in this region.

\section{Materials and Methods}

\subsection{Study Area}

Hailakandi district is located in between longitude $24^{\circ} 13^{\prime} 13.4^{\prime \prime} \mathrm{N}$ - 24 $51^{\prime} 26.7^{\prime \prime} \mathrm{N}$ and latitude $92^{\circ} 32^{\prime} 14.9^{\prime \prime} \mathrm{E}-$ $92^{\circ} 36^{\prime} 21.0^{\prime \prime} \mathrm{E}$ at an elevation of $21 \mathrm{~m}$ of the state. The district is surrounded by Cachar district to the north and east, Karimganj district to west and the neighboring state Mizoram in the south (Fig 1). Major portion of the district has flat areas while hills are only at the south. The main hilly tract is the northern foothill of Mizo (Lushai) Hills of Mizoram (India). From the middle of the hill ridges, the Dhaleswari, (a tributary originated in Mizoram) flow from little southwest to north framing a unique structure along the bank, locally called thalls. Laterally with its course, numerous villages occupy both the banks of the river, while some villages are also the fringes of Inner line Reserve forest and Katakhal Reserve forest, which are officially declared as forest villages. This tributary then joins the Barak River, the main River of the valley.

Following are characteristics floral species constitute forest cover of the district: Dipterocarpus turbinatus, Palaquium polyanthum, Ficus religiosa, Sapium baccatum, Vitex heterophylla, Ficus glomerata, Dillenia pentagyna, Kayea floribunda, Ficus benghalensis, Gmelina arborea, Lagerstroemia speciosa, Albizia lebbek, Albizia odoratissima, Albizia procera, Artocarpus chama, Artocarpus heterophyllus, Artocarpus lakoocha, Azadirachta indica, Albizia saman, Emblica officinalis, Mangifera indica, Melia azedarach, Mitragyna rotundifolia, Sapindus mukorossi, Semecarpus anacardium, Syzygium cuminii, Tetrameles nudiflora, Toona ciliate, and large patches of bamboo like Melocanna bambusoides, Bambusa vulgaris, Bambusa balcooa, Neohouzeaua dullooa.

The monoculture of Areca catechu, Tectona grandis, rubber are mostly seen at plains while at tillahs (hills) Piper beetle as jhum (a slash and burn type of shifting cultivation) cultivation is very common.

The cultivated flatten land is dominated by paddy while other field crops are oilseeds, pulses, sugarcane and maize covers only a few portion of the land. Both kharif and rabi vegetables are grown along with some common fruit plants like mango, banana, jackfruit, pineapple, Assam lemon, and guava. Tea plantation comprises of $13.4 \%$ from total land of the district. The climate of the area is tropical monsoon type; the average temperature varies from $37^{\circ} \mathrm{C}$ in summer which is hot and wet to $7{ }^{\circ} \mathrm{C}$ in winter generally cool and dry. The average annual precipitation is $2400 \mathrm{~mm}-2800 \mathrm{~mm}$, with most of the rain occurring during summer (April to October) ${ }^{[13]}$.

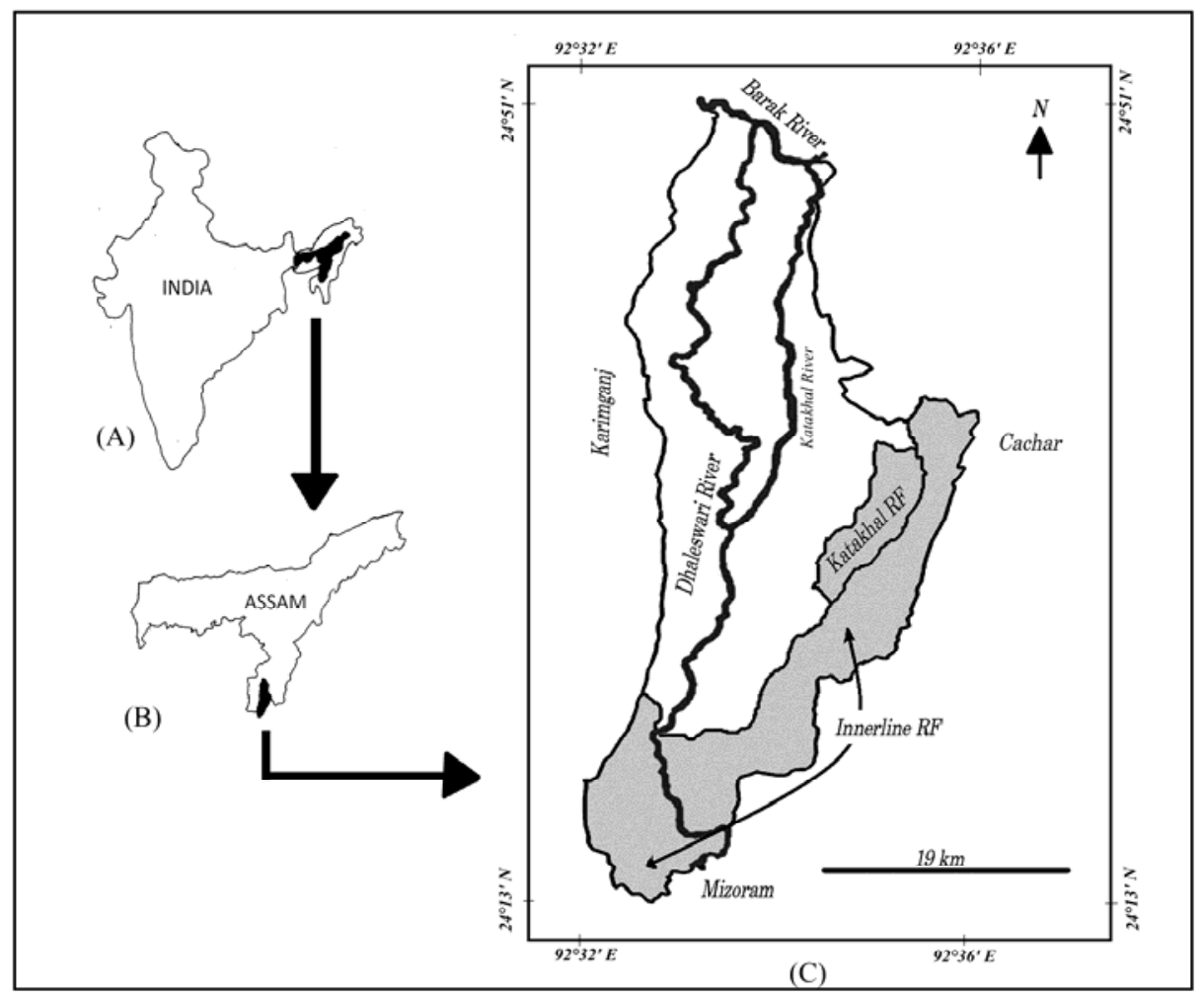

Fig 1

$\sim 500 \sim$ 


\subsection{Data collection}

Depending on the feasibility, every possible site was visited and the survey was carried out for eight months from December 2015 to April 2016 and October 2016 to December 2016. It also includes some records after the assigned study period. Intensive fieldwork was done mostly on foot during morning hours $0500-1000$ that continues up to late evening 1400-1700. Existing and newly cut trails/roads were used to record the sightings. The presence of the primates was ascertained by direct sighting or by hearing the calls ${ }^{[17]}$. As per requirement, motor vehicles were also used to reach the sites. For species identification, field guides $[13,18,22]$ were used. Colour visual was used for identification while interviewing fringe forest villagers. Observations of the fieldwork were noted down in a field notebook along with field maps and drawings. A pair of binoculars $(32 \times 8)$ and one still camera were used.

The status of primate occurrence was determined on the basis of frequency of presence in study sites $(n=16)$ : common (90$100 \%)$; fairly common $(60-80 \%)$; uncommon $(30-50 \%)$; rare $(20-40 \%)$; very rare $(>20 \%$ or $0 \%)$. Further, a total abundance of each primate species (summation of number of individual per site) was mentioned.

\subsection{Priority rating}

For conservation priority status, priority rating has been given for each primate species following ${ }^{[7]}$ for Indian primates. Although this rating were intended for the period of 1987-91 since then no such rating has been prepared so it is valuable to prioritizing primate conservation in the present context. The species have been rated on the following three parameters: (A) degree of threat to the population (rated on a scale of 1 6), (B) taxonomic uniqueness of the species (rated on 1 - 3 scales) and (C) association of species with other threatened forms (rated on 1 - 2 scale). Details of the rating criteria are given in Choudhury 1988c ${ }^{[7]}$. Based on this scale, a highly endangered species can score a maximum of 11; therefore, the species having a score near to or equal to11 require an urgent conservation effort for its future survival.

\section{Results \\ 3.1 Occurrence and Ecology of the primates \\ 3.1.1 Rhesus Macaque (Macaca mulatta)}

IUCN (2017): Least Concern. Legal status: IWPA: Schedule II; CITES (India): Appendix II

Vernacular name (in Bengali): Bandor, Banor, Lal bandor. This was the most common and abundant primate species of the study area. During the survey, 331 individuals were encountered with $90 \%$ occurrence; however, it was difficult to estimate the actual group size because troop remain scattered as the species was persecuted by the local residents for stealing food, utensils from houses; raiding the crops and fruiting trees which was very common scenario. On every occasion, Rhesus was spotted on the ground in which foraging and feeding accounts for maximum activity, followed by grooming and resting. Sometimes, it was also seen at the lower strata of fruiting trees. Common fruiting trees were used for feeding. Some preferred food plants were Artocarpus heterophylla, Dillenia indica, Syzygium cumini, Tectona grandis, Musa sp., Mangifera indica, Litchi sp., Zizyphus mauritiana. Sometime young leaves of Bambusa sp. were also preferred, also reported to feed crops like Paddy (most cases), Cucurbita maxima, Solanum tuberosum.

\subsubsection{Capper Langur (Trachypithecus pileatus)}

IUCN (2017): Vulnerable. Legal status: IWPA: Schedule I part I; CITES (India): Appendix I

Vernacular name (in Bengali): Honuman, Uluman

Capped langurs were the second most abundant monkey after Rhesus macaque and regarded as fairly common with $68 \%$ occurrence. A total of 35 (including one infant) individuals were seen during the survey, however, sex could not be differentiated due to difficulty of clear-vision. At Balikandi, three troops were encountered at three different locations: Hillpunji, Ramchandi punji and Ramchandi (part-II). In the first location, eight individuals were seen while at the second 10 individuals (even reported to 12 individuals) and at third location, a troop size of 12 individuals was seen. All these locations were at least one-two kilometers apart. At Garmurah forest range office, the extreme south part of the district two mature female individuals including one infant was spotted. At Manipuri shit, almost $8-9 \mathrm{~km}$ far from Garmurah range office, two mature individuals were seen feeding on bamboo leaf. Apart from direct sighting, confirms reports from Anakhal TE, Ratanpur TE, Katlicherra TE, Dolhai TE, Rupacherra TE, Kukicherra, Nargorhgena and Garothpunji During the period of survey, the species always seen at the tree-top also never reported to raid crops with an exception in one case at Manipuri shit where local resident claims that, it feed on mustard seeds. Feeding was generally done in two bouts morning and evening on the following common plant species: Artocarpus heterophylla, Dillenia indica, Syzygium cumini, Tectona gradis, Gmelina arborea., Mangifera indica, Bombax ceiba, Ficus sp., Artocarpus chaplasa, Albizia sp., Toona ciliate, Piper beetle, Litchi sp., Zizyphus mauritiana in which young leaves and fruits were mostly preferred.

\subsubsection{Phayre's Leaf monkey (Trachypithecus phayrei)}

IUCN (2017): Endangered. Legal status: IWPA: Schedule I part I; CITES (India): Appendix I

Vernacular name: Chosma Bandor, Kaala bandor.

In comparison to first two primate species, Phayre's langur was difficult to see perhaps due to its shy nature. Therefore, it was regarded as uncommon (43\% occurrence) to the study area. This species mostly preferred to tropical evergreen or semi-evergreen forest, deciduous forest but here in every occasion we seen it on secondary forest which were mainly mixed forest of bamboo and fruiting trees like Artocarpus heterophylla, Syzygium cumini, Mangifera indica, Ficus sp., Artocarpus chaplasa, Litchi sp., Zizyphus mauritiana. Three individuals were directly sighted at Monacherra, one on the ground while other two individuals at the bamboo stand. On 29-dec-2015 morning, forest official seen six to eight individuals at Manipuri shit near Gharmura, however, on the same day we arrived at the same spot could see only single individual. Therefore, only four individuals were directly sighted. Similarly at Nargorhgena, local people were very familiar with the species; according to villagers a small troop of three-four individuals were frequent visitor. Besides its occurrence was also confirmed from Rupacherra TE, Dholai TE, Kukicherra and Garothpuji, confirm reports were obtained for its occurrence.

\subsubsection{Western Hoolock Gibbon (Hoolock hoolook)}

IUCN (2017): Endangered. Legal status: IWPA: Schedule I part I; CITES (India): Appendix I

Vernacular name: Ulluck, Uluman.

Hoolock gibbon was rare to this area with $37 \%$ occurrence. Three individuals were directly sighted. Two troops were 
directly seen at the forest track of Ratanpur TE, which is a fragmented part of Katakhal Reserve forest: One pair male and female and one juvenile from another troop. At Balikandi, a continuous call for 10 minutes of a single individual was heard. Other than this sighting, confirm reports from Nargorhgena, Rupacherra TE, Kukicherra and Garothpuji.

\subsubsection{Other Primates}

Out of the 8 reported species of non-human primates, four were observed in the field, while the other four (as mentioned below) could not be sighted.

\subsubsection{Slow loris (Nycticebus bengalensis)}

IUCN (2017): Vulnerable. Legal status: IWPA: Schedule I part I; CITES (India): Appendix I

Vernacular name: Lajapoti bandor, Lajuki bandor.

During the survey, no direct sighting however, a report of one killed at Balikandi in 2007 and in subsequent year, one caught at Anakhal TE (per comm.); again one caught from Sonari village, fringe forest village near Innerline reserve forest (The Telegraph, Culcutta daily 22 September 2012). On $2^{\text {nd }}$ April 2017, a female juvenile was rescued from Kanchanpur by the authors and transferred to Kaziranga rescue center. Subsequently, on $4^{\text {th }}$ April 2017, another Slow loris was caught by local police from Batirkupa (per comm.). Several confirm reports provided familiarity among the local people had put the species as uncommon to the area but difficult to find for its nocturnal nature.

\subsubsection{Pig-tailed Macaque (Macaca nemestrina).}

IUCN (2017): Vulnerable. Legal status: IWPA: Schedule I part I; CITES (India): Appendix I

Vernacular name: Bandor, Banor

No direct sighting of the species, however, the species came well within the distribution range. Local could not identified the species due to its alikeness with Rhesus macaque, so people got confuse while some were of opinion that they saw the species from forest villages namely Ramnathpur and Garothpunji of Innnerline Reserve forest. Therefore, it was put into very rare category.

\subsubsection{Stump-tailed macaque (Macaca arctoides)}

IUCN (2017): Vulnerable. Legal status: IWPA: Schedule II part I; CITES (India): Appendix II

Vernacular name: Bandor, Banor

No sighting of the species came in but the numerous locals and local hunters had sighted the species from the study area. Hence, the species was put into very rare category for the area.

\subsubsection{Assamese Macaque (Macaca assamensis)}

IUCN (2017): Near Threatened. Legal status: IWPA: Schedule II; CITES (India): Appendix II

Vernacular name: Bandor, Lal Banor

The species was considered to be very rare since no records during the survey although local hunters and resident of forest villagers had sighted the species.

\subsection{Conservation Priority rating}

From Table 1, it appeared that all the Indian primate species had an overall rating of more than 5 except for Macaca mulatta. Hoolock hoolock had scored highest with 9, followed by Macaca arctoides with 8, then 7 for Macaca nemestrina while four primate species: Nycticebus bengalensis, Macaca assamensis, Trachypithecus phayrei, had scored 6 and
Trachypithecus pileatus had scored only 4. However, in context to present study area, the scoring was slightly differing as in table 1 (Scoring $\left.^{2}\right)$. According to Scoring ${ }^{2}$ Hooclock hoolock had the highest total rating of 9 followed by Macaca artoides with 8 . Three primate species had an analogous total rating of 7: Nycticebus bengalensis, Macaca assamensis and Macaca nemestrina. Trachypithecus phayrei and Trachypithecus pileatus came with 6 and 5 as total priority rating score. Macaca mulatta scored the lowest total 3 as the least priority species in primate conservation in the present study area.

Therefore, the sequence of priority primate species for conservation:

Hooclock hoolock > Macaca artoides > Macaca assamensis $\geq$ Macaca nemestrina $\geq$ Nycticebus bengalensis $>$ Trachypithecus phayrei $>$ Trachypithecus pileatus $>$ Macaca mulatta

\subsubsection{Basis of Rating}

Nycticebus bengalensis had an overall scoring of 7. In Degree of threat, we assigned a score of 2 as its population was definitely at risk due to alteration or destruction of its preferred habitat and hunting. The exactly population status still remain unclear due to its nocturnal behaviour but it was widely distributed in the study area. For Taxonomic uniqueness we had given 3 as it was the only member of the genus present in the study area. For association with other threatened primates we assigned 2 , within the study area its prime habitat was overlapped with other threatened speciesMacaca assamensis, Trachypithecus phayrei, Trachypithecus pileatus, Hoolock hoolock, Macaca arctoides Macaca nemestrina.

Macaca arctoides had a total scoring of 8. Our assigned score exactly matches with Scoring ${ }^{1}$. For degree of threat, their preferred habitats turn into small. Stretches of Innerline RF and Katakhal RF were breaking off into small forest patch for agricultural purpose (especially slash and burn practiced by tribals). Therefore, the population often got trapped and exposed for hunting, which would likely to decline its population. For taxonomic uniqueness, the species was very distinct from other closely related forms. Regarding association with other threatened primates within the study area, the habitat overlapped with other threatened speciesMacaca assamensis, Trachypithecus phayrei, Trachypithecus pileatus, Hoolock hoolock, Nycticebus bengalensis, Macaca nemestrina.

Macaca assamensis, overall the species had scored 7 in our list. For degree of threat and taxonomic uniqueness, we assigned a same score as in scoring ${ }^{1}$ as it was distinct species and population likely to be limited distributed within the study area due to incessant habitat destruction and poaching. However, in the present context, its preferred site in the study area was overlapped with other threatened primatesTrachypithecus phayrei, Trachypithecus pileatus, Hoolock hoolock, Nycticebus bengalensis, Macaca nemestrina, Macaca arctoidesn hence we assigned a score of 2 in 'associated with other threatened forms'.

Macaca mulatta had scored 3 in total. Our signed scored had matched with scoring ${ }^{1}$. For degree of threat, 1 was assigned as the species was unlikely to be decline because of its adaptation to broad habitat type (mostly at the vicinity of human habitation) in the study area. The species occur in large group and rarely overlap with other threatened species hence we assigned 1 each for 'taxonomic uniqueness' and 'associated other threatened form'. 
Macaca nemestrina overall the species had scored 7 in total which exactly matched with scoring ${ }^{1}$. In the study area its preferred habitat had suffered heavy habitat destruction resulted into congregate of its population into small portion, therefore distributed at certain limit; if such situation continued then its future sustenance would be difficult. The species was distinct and its habitat overlapped with many threatened forms- Trachypithecus phayrei, Trachypithecus pileatus, Hoolock hoolock, Nycticebus bengalensis, Macaca assamensis, Macaca arctoides.

Trachypithecus phayrei, was assigned the score of 6 similar to scoring ${ }^{1}$. Its population was distributed to certain limit in the study area. Due to habitat destruction it became vulnerable to poaching. The species was distinct and its habitat overlapped with many threatened forms- Macaca nemestrina, Trachypithecus pileatus, Hoolock hoolock, Nycticebus bengalensis, Macaca assamensis, Macaca arctoides.

Trachypithecs pileatus had scored 6. As the population endured in a limited portion land, but broader than other species with same scoring in the study area. Also the species was at risk of habitat destruction and hunting, so we assigned a score of 2 in 'degree of threat' while 1 in 'taxonomic uniqueness' as the species had several closely related and 2 in 'associated with other threatened form' as its habitat got overlapped with other species- Trachypithecus pileatus, Hoolock hoolock, Nycticebus bengalensis, Macaca assamensis, Macaca arctoides.

Hoolock hoolock scored 9 in total similar to scoring1. Prime habitat in the study area, got fragmented, devoid of tall trees due to habitat destruction so the distribution was scattered causing them to exposed for poaching which if continued the scoring would reach at max in the scale of 'degree of threat'. Further, it was the only representative species of the family, so we assigned 3 in 'taxonomic uniqueness'. As for 'associated with other threatened form' habitat was overlapped with other threatened species- Trachypithecus pileatus, Trachypithecus pileatus, Nycticebus bengalensis, Macaca assamensis, Macaca arctoides.

Table 1: Priority scoring for conservation of Primates of Hailakandi (Scoring1: Choudhury, 1988 for Indian Primate; Scoring 2: Authors' score).

\begin{tabular}{|c|c|c|c|c|c|c|c|c|}
\hline \multirow[b]{2}{*}{ Species } & \multicolumn{4}{|c|}{ Scoring $^{1}$} & \multicolumn{4}{|c|}{ Scoring $^{2}$} \\
\hline & $\begin{array}{c}\text { Degree of } \\
\text { Threat }\end{array}$ & $\begin{array}{l}\text { Taxonomic } \\
\text { uniqueness }\end{array}$ & $\begin{array}{c}\text { Associated with } \\
\text { other threatened } \\
\text { forms }\end{array}$ & Total & $\begin{array}{c}\text { Degree of } \\
\text { threat }\end{array}$ & $\begin{array}{l}\text { Taxonomic } \\
\text { uniqueness }\end{array}$ & $\begin{array}{l}\text { Associated with } \\
\text { other threatened } \\
\text { forms }\end{array}$ & Total \\
\hline Nycticebus bengalensis & 1 & 3 & 2 & 6 & 2 & 3 & 2 & 7 \\
\hline Macaca arctoides & 4 & 2 & 2 & 8 & 4 & 2 & 2 & 8 \\
\hline Macaca assamensis & 3 & 2 & 1 & 6 & 3 & 2 & 2 & 7 \\
\hline Macaca mulatta & 1 & 1 & 1 & 3 & 1 & 1 & 1 & 3 \\
\hline Macaca nemestrina & 3 & 2 & 2 & 7 & 3 & 2 & 2 & 7 \\
\hline Trachypithecus phayrei & 3 & 1 & 2 & 6 & 3 & 1 & 2 & 6 \\
\hline T. pileatus & 1 & 1 & 2 & 4 & 2 & 1 & 2 & 5 \\
\hline Hoolock hoolock & 5 & 2 & 2 & 9 & 5 & 2 & 2 & 9 \\
\hline
\end{tabular}

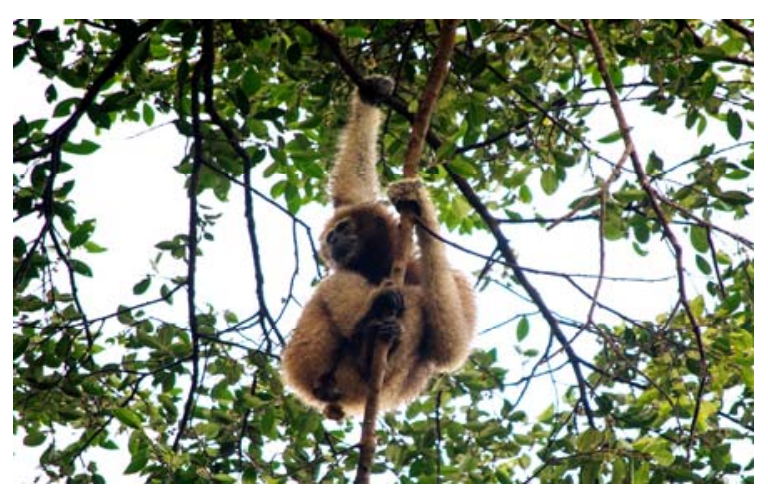

Fig 2: Hoolock hoolock (Female) at Ratanpur Tea estate.

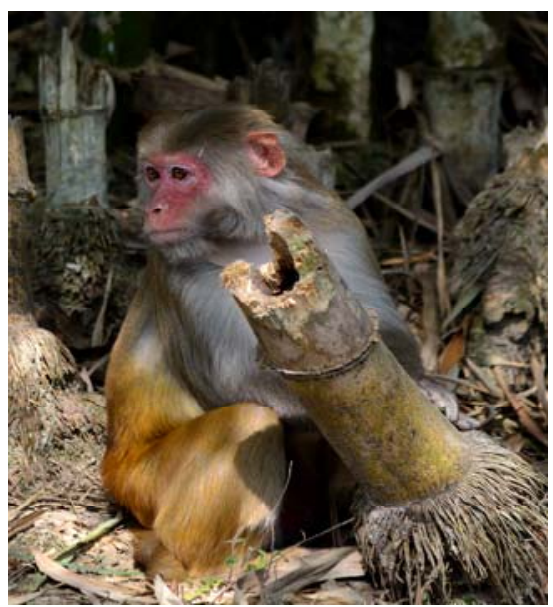

Fig 3: Macaca mulatta, a common primate species of the study area.

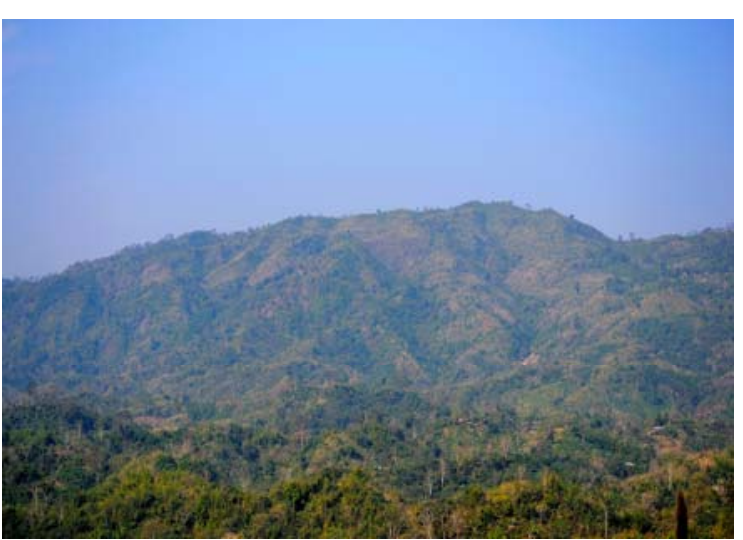

Fig 4: Degraded forest patch at Innerline Reserve forest.

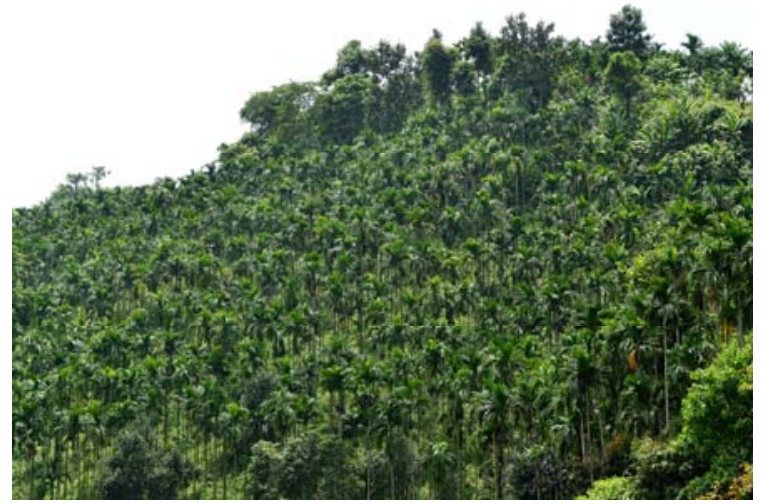

Fig 5: A monoculture of Areca catechu at the periphery of Katakhal Reserve forest 


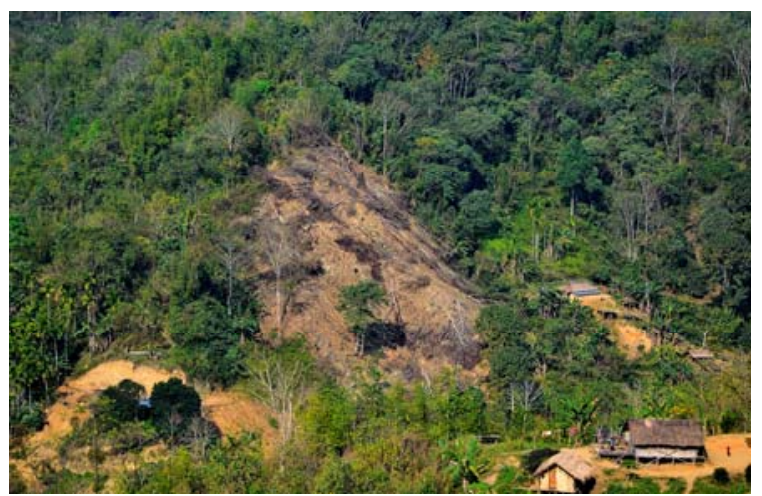

Fig 6: Reclamation of forest land by local community at Innerline Reserve forest

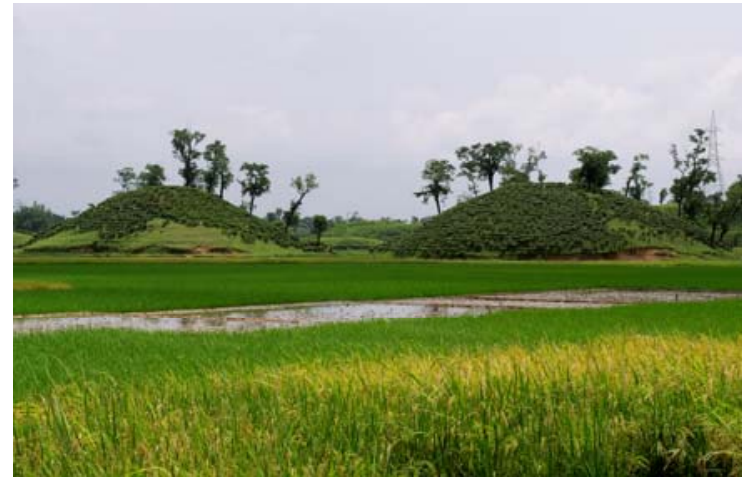

Fig 7: Tea garden and paddy field fragmenting the Katakhal Reserve forest

\section{Discussion}

Eight primate species has been known to inhabit the study area $[4,11,13,20]$; however, only four species were observed during the study period. No sighting of Nycticebus bengalensis but some confirmed secondary records support its recent status of occurrence. While three species like Macaca nemestrina, Macaca arctoides, Macaca assamensis remain undetected even though previous literature review has confirmed their occurrence from the study area especially from Innerline and Katakhal Reserve forest $[4,11,13,20]$. We had visited their preferred habitats and areas mentioned in the documents, still result remain unchanged. But during the visit it was also evident that large part of the prime primate habitat i.e., Innerline RF (western bank of Dhaleswari River) exposed to human settlements, slash and burn practice and monoculture plantation.

Habitat loss by clearing or conversion of natural primate habitat may be for settlement, agriculture or tea plantation is the major reason for primate population decline in the present study area. Such conditions eventually give rise to other associated problems like human-primate conflict and fragmentation of forest. The economy of Hailakandi is largely based on agriculture. About $446.70 \mathrm{~km}^{2}$ of land is used for this purpose out of which $365 \mathrm{~km}^{2}$ is under paddy cultivation while tea plantation, covers about $59.20 \mathrm{~km}^{2}$ of land. In the reserve forest, tribes like Reangs and Chakma usually practice slash and burn agriculture that migrates all the way from neighboring hills of Mizoram and Tripura. Collection of firewood and bamboo from the reserve by settlers is very common. Besides illegal felling of trees, mostly for the supply of woodcraft preparation has made both the reserve forest devoid of tall and mature trees. Also, forest department burns the forest for plantation, usually Tectona grandis is planted that may in long run turn the area as monoculture area.
Illegal encroachment is the other serious problem of the existing forest. It is estimated that in Innerline RF, $85.64 \mathrm{~km}^{2}$ of land is under encroachment by 23658 people residing in 4944 households. Similarly, in Katakhal RF, $30.52 \mathrm{~km}^{2}$ of land with 11732 people residing in 2214 household, i.e., a total of $116.16 \mathrm{~km}^{2}$ i.e., $21.5 \%$ of land from both reserve forests is under encroachment ${ }^{[15]}$.

Besides there are nine forest-villages in Innerline RF covering about $11.6 \mathrm{~km} 2$ of land having 1419 household resided by 4257 people while in Katakhal RF, $63.77 \mathrm{~km}^{2}$ of land is under 11 village having 5045 people residing in 1750 household ${ }^{[15]}$. Most of the villagers are also expanding and occupying the land from Reserve forests ${ }^{[5]}$.

So far no large scale poaching has been noticed from the study area, however, near the southern border of Innerline RF Mizoram tribes hunt all the primate species for food; sometimes they are also captured to be kept as pets ${ }^{[5]}$. Even some local resident hire or allow Khasi and Jantiya tribes from neighboring state Meghalaya to shoot primate especially Capped langur and Rhesus macaque. Through interaction with the local people, it was gathered that people of Balikandi, Panchgram and other area like Anekhal, Katlichera, Gurmurha within the study area accepted the primate species like Capped langur and Rhesus macaque as pest as these primates usually damage their fruit trees and crops.

Therefore, all these can be considered as sufficient reason for the decline of primate population within the study area. Local extirpation of available primate species is not far-off as their available natural habitats are in serious threat from illegal lumbering and encroachment.

In order to enumerate primate conservation we assigned a conservation priority rating to each primate species, so that the best use of the limited resources available for primate conservation can be made for highly threatened primate species. However, in the process, we came across some difficulties: for example in Table 1(Scoring $\left.{ }^{2}\right)$, Nycticebus bengalenesis has been given a score of 3 under 'taxonomic uniqueness', while Trachypithecus phayrei was scored 2, thereby giving a total score of 7 for Nycticebus bengalensis, while Trachypithecus phayrei has total score of 6 , despite the fact that the latter is more endangered. Secondly, in prioritized primate species of the study area using criteria as adopted by ${ }^{[7]}$, some difference has been noticed in scoring ${ }^{1}$ and scoring ${ }^{2}$, for example: Macaca Assamensis, in 'association with other threatened form' we assigned 2 while Choudhury $1988 c^{[7]}$ has given 1 as it has given concerning whole nation while we have given on the basis of our study area, similarly difference in scoring seen in Nycticebus bengalensis and Trachypithecus pileatus.

Thus, on the basis of conservation priority rating, primate species scoring near to 11 claims to be the high priority species for primate conservation, thus, in the present context, Hoolock hoolock is the first priority species followed by Macaca artoides these two species require an high conservation attention. Other species like Macaca assamensis, Macaca nemestrina require conservation attention even though these came after Nycticebus bengalensis in total rating because of their rarity in the study area. Trachypithecus phayrei also need urgent conservation efforts as the study area is the only range of this species in entire Assam. Further, by conserving above mention species the remaining two speciesNycticebus bengalensis and Trachypithecus pileatus will also get conservation as they mostly shares the same habitat in the study area. Besides, these species also scored more than one in 'degree of threat' which mean the threats prevailing in the 
study area upon the species is very serious which if continue in the present rate their sustenance in future is difficult or it may lead to local extinction from this past of Assam.

Even though many threats has been identified still no serious conservation effort has been undertaken in this part of Assam except for a proposal of Dhaleswari wildlife sanctuary that is yet to be officially declared [2]. Reserve forests in the study site have suffered from ill-management and are exaggerated by local insurgency problems, therefore, forest officials often find difficulty to do regular monitoring, further, lack of research activities has left this area away from strong conservation implementation.

\section{Conclusion}

In spite of all these, there is no deniable fact that the district is still a stronghold of these eight primates even though threats remain to be in operation in variable degrees. Thus, if the area is properly managed, there is every probability that it will be among the few places on earth harboring high diversity of primates, a small landscape that would ensure their long-term future sustenance and increased population; that may be called as "Paradise of Primates" in near or distant future.

\section{Recommendation}

1. Proposal for upgrading existing Reserve forest to Wildlife Sanctuary should be implemented by the Government of Assam as these reserve forests form a prime habitat of many threatened primates species: Hoolock hoolock, Macaca artoides, Nycticebus bengalensis, Macaca assamensis, Macaca nemestrina and Trachypithecus pileatus. Further, within Assam, entire population of Trachypithecus phayrei is limited to this part. However, looking at the present scenario of the reserve forests, large number of people has taken refuge in the periphery of the RFs as if forest villages (approximately 3169 households), so updating into wildlife sanctuary may be difficult. So, in this case, present RFs may be updated to 'community reserve' which will allow greater participation of local communities in management of protected area thought traditional or cultural conservation practice. In this way, some problem regarding unemployment will also be solved.

2. Mass awareness campaign about the importance, threat of primates and consequence of killing a protected species must be conducted in the area where conflicts between human and primates are noticed. In the study area, most of the people are unaware of the fact that primates are protected and killing of any could impose penalty.

3. More research on flora and fauna of this district should be done. Extensive survey on primates of this study area was conducted long back in 1990s since then no proper documentation has been done. Therefore, we urge the local nature-based NGOs and University to conduct more research and explore the area to its maximum.

4. Ecotourism should be encouraged as Phayre's leaf monkey could be one of the major attractions for tourist as in Assam as it is found in this area only.

\section{Acknowledgment}

Authors would like to thank all people in the survey who supported our work and helped us to get results of better quality. Further, we would like to thank Rofik Ahmed Barbhuiya, Khairruzzaman Mazumder, Pooja Das, Nazimur Rahman Talukdar and my lab mates for their valuable comments in framing this article. Nevertheless, we are also grateful to forest department of Hailakandi district and Wildlife Conservation Laboratory, department of Ecology and Environmental Science, Assam University, Silchar for giving satisfactory conveniences for the study.

\section{References}

1. Bose J. Serach for a Spectacle'. A conservation survey of Phayre's leaf monley (Trachypithecus phayrei) in Assam and Mizoram. Occasional report no. 14. Wildlife Trust of India, 2003.

2. Choudhury AU. Plea for a new wildlife sanctuary in Assam. World Wildlife Fund- India. Newsletter No 1983; 47:4(4).

3. Champion HG, Seth SK. A revised survey of the forest type of India. Reprinted 2005 Nataraj publication, Dehradun, New Delhi. 1986, 1-404

4. Choudhury AU. Notes on the distribution and conservation of Phayre's leaf monley and Hoolock gibbon in India. Tigerpaper. 1987; 14(2):2-6.

5. Choudhury AU. A primate survey in southern Assam, India. Primate conservation. 1988a; 9:123-125.

6. Choudhury AU. Phayre's leaf monkey (Trachypithcus phayrei) in Cachar. Journal of Bombay Natural History Society. 1988b; 85(3):485-492.

7. Choudhury AU. Priority rating for conservation of Indian primates. Oryx 1988c; 22:89-94.

8. Choudhury AU. In search of Silvered leaf. Hornbill. $1991 ; 1: 28-31$

9. Choudhury AU. Phayre's leaf monkey in Northeastern India. Tigerpaper. 1994; 21(3):1-4.

10. Choudhury AU. Checklist of the Mammals of Assam. Revised $2^{\text {nd }}$ edition, Gibbon Books and Assam Science Technology \& Environment Council, Guwahati, India, 1997, 1-103.

11. Choudhury AU. Primates in Northeast India: An overview of their distribution and conservation. ENVIS Bulletin: Wildlife and Protected Areas. 2001; 1(1):92101 .

12. Choudhury AU. The status of endangered species in Northeast India. Journal of Bombay Natural History Society. 2006; 103(2, 3):157-167.

13. Choudhury AU. The Mammals of Northeast India. Gibbon Books and The Rhino Foundation for Nature in North East India, Guwahati, India, 2013a, 1-420.

14. Choudhury AU. The Mammals of India a systematic \& cartographic review Gibbon Books and The Rhino Foundation for Nature in North East India, Guwahati, India, 2016, 1-328

15. DFR. District forest register. Prepared by Forest Department, Hailakandi. (Unpublished), 2015.

16. ISFR. Indian state of forest report 2015. Forest survey of India, Dehraun, Uttarakand, India, 2015.

17. Islam M, Choudhury P, Bhattacharjee PC. Survey and census of Hoolock gibbon (Hoolock hoolock) in the Inner-Line Reserve forest and the adjoining areas of Cachar district, Assam, India. Folia Primatologica. 2013b; 84:170-179.

18. Menon V. A field guide to the India mammals. Dorling Kindersley (India) Private limited, Delhi, India, 2003, 1201

19. Mittermeier RA, Gil PR, Hoffmann M. Hotspots Revised: Earth's biologically richest and most endangered terrestrial ecoregions. Comex Books on Nature, USA, 2004, 1-392

20. Muhammed KM. Diversity, habitat preference and 
Journal of Entomology and Zoology Studies

conservation of primates of southern Assam, India: the story of a primate paradise. Journal of Asia-Pacific Biodiversity. 2014; 7:347-354.

21. Myers N, Mittermeier R, Mittermeier CG. Biodiversity hotspots for conservation priorities. Nature. 2008; 403:853-858.

22. Prater SH. Book of Indian animals. $2^{\text {nd }}$ edition. Bombay Natural History Society, India. 1948, 1-422. 